\title{
Review: James Miller, China's Green Revolution: Daoism and the Quest for a Sustainable Future
}

\author{
书评: 詹姆士.米勒， \\ 中国的绿色革命：问 “道”，探索可持续性发展的未来 \\ Stephen K. Levine \\ The European Graduate School, Switzerland
}

\begin{abstract}
This review outlines Miller's argument that the Daoist tradition offers an important perspective for ecological thought based on the pervasion of nature in human existence and the porosity of the human body. Somatic practices can build a basis for the aesthetic perception necessary for ecological action. The reviewer suggests that there is a possible convergence between Daoism and the thinking of poiesis that shows the importance of the creative and expressive arts in ecological theory and practice.
\end{abstract}

Keywords: Daoism, ecology, wu-wei, cultivating the Dao, somaesthetics, poiesis

\section{摘要}

这篇书评概括了米勒的论点，他认为道家传统基于人体与自然互通互联，互相依存的观 点，为生态观提供了重要的思考角度。践行修身为生态行为所需的美学感知建立了基 础。评论家提出道家思想和 ( 古希腊 ) “创造” 的观点可能有异曲同工之处，表明了创 造性和表达性艺术在生态理论和实践中的重要性。

关键词: 道家思想，生态学，无为，修道，身体美学，创造

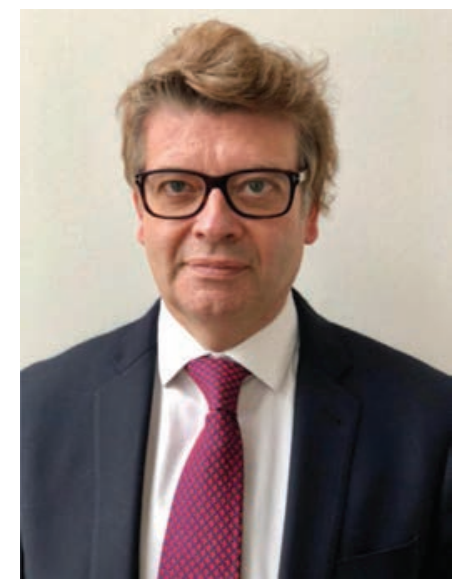

FIGURE 1 | James Miller (https://scholars.duke.edu/person/James.Miller). 


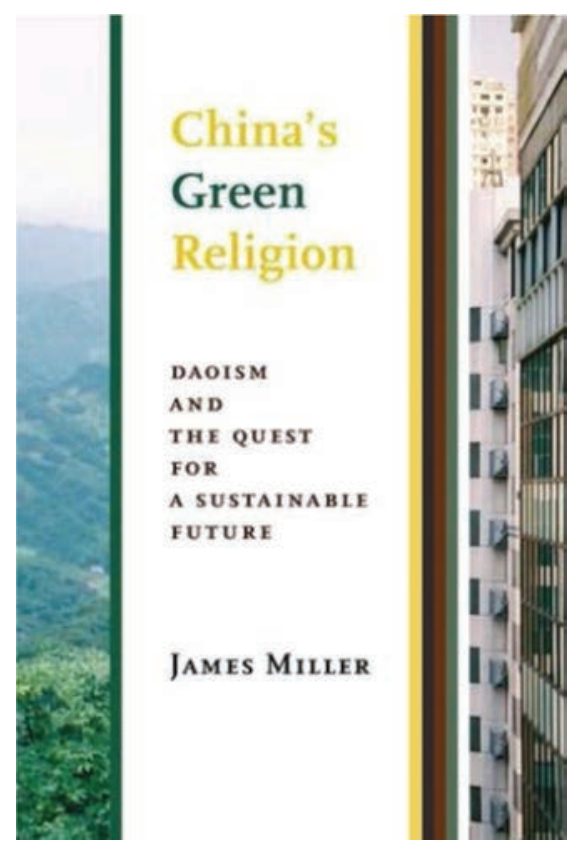

FIGURE 2 | Book cover of China's Green Revolution: Daoism and the Quest for a Sustainable Future (https://cup.columbia.edu/book/chinas-green-religion/9780231175869).

James Miller's book is an important contribution to ecological thought from the standpoint of the Daoist religion. In Miller's view, the current search for a sustainable future for human beings and the planet as a whole is undercut by the Western tradition in which nature is conceived of as something outside of human existence. In this tradition, nature is an object that confronts human beings as subjects. Nature becomes a resource for human development. Sustainability, then, is understood in terms of the preservation of a nature that is being despoiled.

From a Daoist perspective, however, nature is to be understood as creative selfemergence. It has its own subjectivity, a subjectivity that it shares with all beings, including humans. The human body is porous, and nature pervades our existence. We are not outside of it, confronting nature as an other. Instead, Miller sees Daoism as providing a liquid ecology, one in which the Dao flows into and out of all beings as Qi, or liquid vitality. This is a radically different conception from the Western one governing modernity.

Miller is careful to note that he is not proposing a form of "Orientalism," an essentialist reading of an "ancient” Chinese culture that we must recover. Rather China itself follows the Western model, and the ruthless destruction of much of the Chinese landscape is seen as a necessary consequence of development. This process is justified by an interpretation of the Confucian tradition, in which patriarchal authority is vested in the leader who follows the mandate of heaven that has been granted to him.

Daoism, instead, is a dissonant element in Chinese culture, one that provides an alternative model for development, based on neither authoritarianism nor passive 
acceptance. Rather, the Daoist conception of action is understood in terms of the principle of wu-wei, usually translated as "non-action." Wu-wei is sometimes understood as leading to quietism and withdrawal from society. Miller, however, sees it as a process of catalysis. Change agents who act in accordance with wu-wei are catalysts. They do not bring about change but, rather, intervene in such a way that subjects are empowered to undertake the action that is necessary for their own creative self-transformation.

This seems to me to be similar to Thoreau's and Ghandi's conception of nonviolence, which was used by Martin Luther King in the civil rights movement in the United State and by others elsewhere, and also the philosophy of experiential education, in which the responsibility of the teacher is not primarily to instill knowledge into the student but to help him or her to develop their resources in their own specific way. It is also like the therapeutic process. In expressive arts therapy, in which therapists' interventions stem from the "aesthetic responsibility" to help clients find their "aesthetic response," their affective-bodily experience gives them a sense of their resources that is necessary to make life-change possible.

In fact, Miller sees the greatest barrier to sustainability to lie in modern individuals' experience of themselves as isolated subjects separate from the world around them. One of the characteristic features of modernity is the creation of a "buffered" sense of self (the term is Charles Taylor's), a self-protective device that aims at insulation from the impingements of urban life. In perhaps the most interesting part of the book, the author develops the notion of "cultivating the Dao," a process of self-development through meditation on texts and through physical disciplines such as yoga or t'ai chi. Here he makes reference to the work of Merleau-Ponty who saw the body as providing our access to the world, in contradistinction to the cogito of Descartes. Our bodily inherence in the world is a recursive process in which we both touch and are touched. Indeed, Miller suggests that Descartes' cogito ergo sum (I think therefore I am) be replaced by tango et tangor (I touch and am touched).

However, Miller goes beyond Merleau-Ponty's phenomenology of the body, using Richard Shusterman's critique of the notion of the spontaneous activity of perception by stressing that, in the modern world, we need a discipline of "somaesthetics," a training of bodily experience that gives access to a connection between self and world. Miller also criticizes Merleau-Ponty's “reluctance to speak about the depth of the inner body where the material experience of the world is actually generated" (p. 116). He quotes Sundar Sarukkai who speaks of yoga as providing a "continuous, conscious grasp of the inner body" (p. 117). To Miller, in contrast to modernity's "buffered” body, such disciplines "can provide the aesthetic or sensory foundation for ecologically sensitive patterns of behavior" (p. 118). Therefore, to overcome our experience of separation from the world around us, we need not only new ways of understanding our inherence in the world but also somatic disciplines that will give us an experience of the porosity of our bodily belonging. This will provide an "affective" relationship to the environment that can underpin the new cognitive understanding that we need.

Miller is clear that the changes in our relation to our environment that are necessary for sustainability cannot be achieved through individual activity alone. Rather, he writes of the ethical and political transformations that a Daoist-inspired ecology requires. In 
addition, he reminds us that change also means a transformation in our sense of the sacred, a theological or cosmological transformation. Miller was trained as a theologian and understands the need for a radical revisioning of our place in the universe. He sees in Daoism what we may call a post-Christian or post-monotheist basis for the "green" or "dark green" vision that has been set forth in some versions of ecological thought. This aspect of his thinking could be developed further in future work.

I also see the possibility for a more developed conception of the role of the arts in a Daoist ecology. When the arts are grounded in the concept of poiesis, their function in human existence is seen as more profound than the mere representation of things and events. Rather, poiesis is the fundamental way in which human existence takes place. We shape ourselves in response to the way the world around us affects us and, in so doing, shape the world anew. This activity of shaping is a receptive one, not to be understood as creation, in which form is imposed on inchoate matter. Rather we are guided by what comes to us as an image or felt sense and respond accordingly, "following the image," in James Hillman's phrase. The profundity of the arts and their impact on human experience rests upon this more fundamental character of human existence as poietic. Perhaps ecology could also be seen as poiesis, not so much a product of technology but rather as an essentially artistic process of receptive formation (see my article, "Nature as a Work of Art: Towards a Poietic Ecology," in E. Levine and S. Levine, eds., New Developments in Expressive Arts Therapy: The Play of Poiesis, 2017). The creative and expressive arts then would have an important role in developing this new worldview.

I have not done justice in this review to the detailed investigation of the Daoist tradition that is contained in James Miller's book. Miller has a deep understanding of this tradition and recounts the ecologically relevant parts in ways that would well reward the readers' attention. For example, his treatment of the tradition called "The Way of Highest Clarity," in which internal visual meditation is utilized to bring the sacred dimension of existence into the body of the adept, is particularly interesting in terms of the notion of cultivating the Dao. I can only recommend an intensive study of this book for a deeper understanding of the contemporary relevance of the Daoist tradition for ecological thought. As Miller himself suggests, such an understanding, accompanied by heightened aesthetic perception, may help us not only in pursuing the goal of sustainability in the sense of preservation, but also a more vital conception of nature as flourishing, one in which human beings and their environment are brought into a mutual process of creative self-development.

\section{About the Author}

Stephen K. Levine, PhD, DSSc, REAT, Founding Dean of the Doctoral Program in Expressive Arts in the Division of Arts, Health and Society at The European Graduate School (Switzerland), Professor Emeritus at York University (Toronto), and Co-Editorin-Chief of the international journal Creative Arts in Education and Therapy-Eastern and Western Perspectives.

Email: slevine.egs.edu@gmail.com 